\title{
What impact does environmental regulation have on technological innovation?
}

\author{
Yuwei Wang \\ Beijing Jiaotong University, School of Economics and Management, Beijing, China
}

\begin{abstract}
The research on the relationship between environmental regulation and technological innovation has a long history, and so far no conclusion has been reached. This article uses 2008-2017 China's statistical data for empirical research, uses technology input to measure technological innovation level, and uses innocuous treatment of domestic waste and sulfur dioxide emissions as explanatory variables to perform regression. The empirical results have obtained the positive impact of environmental regulation intensity on the level of technological innovation, indicating that environmental regulation promotes technological innovation.
\end{abstract}

\section{Introductiont}

Environmental issues have always been fundamental issues affecting the economy and people's lives. In recent years, China's environmental pollution problems have become increasingly prominent. Air pollution, water pollution, and soil pollution have become more and more serious. In order to further control corporate pollutant emissions and strengthen ecological protection, the state has continuously improved environmental regulatory standards for enterprises by different levels of environmental regulation. The "Environmental Protection Law" in 2015 and the "Environmental Protection Tax Law" in 2018 have been successively promulgated and implemented, which has further strengthened the company's emphasis on environmental protection. In the report of the 19th National Congress of the Communist Party of China, General Secretary Xi clearly emphasized that "the ecological environment will fundamentally improve from 2020 to 2035, and the goals of Beautiful China will be basically achieved". A environmentfriendly society provides institutional guarantees and is conducive to promoting the coordinated development of population, resources and the environment. What is certain is that while environmental regulation will improve the ecological environment, it will also affect economic development. An effective environmental regulation policy should protect the environment while minimizing the adverse effects on regulated industries and regional economic development, and realize a "winwin" environment and economy. As technological innovation plays an important role in economic development, and is also the key to reduce pollutant emissions. The impact of environmental regulations on technological innovation has been a hot issue in the theoretical community.

\section{Literature review}

Academia has different views on the impact of environmental regulations on corporate technology innovation. On the one hand, the "restriction hypothesis" represented by neoclassical economics pointed out that tighter environmental policies will inevitably lead to rising pollution control costs for producers. When resource conditions remain constant, high costs will change the resource allocation of enterprises, leading to enterprises reduce investment in research and development activities, reduce production efficiency, and then curb economic growth. On the other hand, in the 1990s, Porter and others reached the opposite conclusion through research, that is, the "Porter Hypothesis" [1]. The hypothesis holds that: from a long-term and dynamic perspective, environmental regulation can effectively promote manufacturers to carry out innovative activities and increase production profits, which can not only compensate for environmental protection input costs, but also improve the productivity and competitiveness of enterprises. Later, Jaffe and Palmer decomposed the Porter hypothesis into three versions: "weak Porter hypothesis", "narrow sense Porter hypothesis" and "strong porter hypothesis" [2]. The first version believes that well-designed environmental regulations can stimulate enterprises to carry out technological innovation activities. The second version refers to flexible environmental regulation policies and means that can provide greater innovation than regulatory and binding policy means. The third version believes that the innovative effects of environmental regulation can cover all compliance costs of the enterprise, leading to increased business performance and enhanced competitiveness of the enterprise.

\footnotetext{
a Yuwei Wang: 17120552@bjtu.edu.cn
} 
The current scholars' research conclusions on the impact of environmental regulation on technological innovation are inconsistent. The most representative viewpoints are as follows: The first viewpoint is that strengthening environmental regulation will inhibit technological innovation. Gray used the American manufacturing industry as a sample from 1958 to 1978 . It was empirically found that the increase in pollution control costs has reduced the total factor productivity (TFP) of the manufacturing sector, of which $30 \%$ was caused by environmental regulations [3]. Jaffe et al. proposed that environmental regulation will produce a "crowding effect" [4]. In order to meet the relevant environmental requirements, enterprises must invest a lot of material, money, human and technical resources in pollution control or pollution reduction, thereby crowding out investment in production and operation, which is not conducive to the improvement of production technology. Kneller et al. Used the British manufacturing industry from 2000 to 2006 as a research sample to conduct an empirical test on this "crowding effect" of environmental regulation [5].

The second view is that strengthening environmental regulation is conducive to promoting technological innovation. This view is based on the "Porter Hypothesis", believes moderate environmental regulation can stimulate technological innovation, improve production efficiency, and offset the costs that environmental regulation may bring. In the long run, the industry's technological innovation capability and international competitiveness can be improved. Miao Miao et al. empirically analyze the relationship between environmental regulations, financing constraints and corporate technological innovation. The results show that the local government's efforts to strengthen environmental regulations can significantly enhance the innovation ability of enterprises, which is specifically reflected by the increase in R \& D investment[6]. Zhao Hong (2007) found that environmental regulation has a significant positive effect on the R\&D expenditure and the number of patent applications lagging behind 3 periods. For every $1 \%$ increase in the intensity of environmental regulation, R\&D expenditure increases by $0.19 \%$, indicating that environmental regulation has a significant impact on technological innovation in the medium and long term. To some extent, the "Porter hypothesis" has been partially confirmed in China[7].

The third view is that the impact of environmental regulations on technological innovation is uncertain. For example, some scholars found that the impact of environmental regulation on technological innovation is different in different industries or regions [8]. Some scholars found that the relationship between the two shows a "U"-type dynamic trend, that is, before the intensity of environmental regulation reaches the inflection point The "innovation compensation" effect has not yet been realized; after the inflection point value, it will significantly promote technological innovation [9]. Some scholars have found in evidence that there is an inverted "U"-type characteristic of the relationship between the two effects[10].

\section{Theoretical Analysis}

Environmental regulation has two opposite effects on technological innovation. When environmental costs are high, environmental regulations inhibit technological innovation of enterprises, and when enterprises actively seek ways to improve the level of pollution treatment, environmental regulations promote technological innovation of enterprises. Whether environmental regulation can promote technological innovation in enterprises depends on the net effect between the two effect.

\subsection{The impact of Inhibition}

The government's regulation of pollution behavior in the production and operation of enterprises through environmental regulations will have certain effects on the economic behavior of regulated enterprises. In order to meet the environmental standards set by the government, regulated enterprises will take certain measures on their own initiative, such as strengthening investment in environmental protection. The implementation of such measures will additionally increase the environmental costs of the enterprise, resulting in two types of costs: explicit and hidden. The former includes direct costs and indirect costs. Direct costs are the passive expenditures of enterprises, such as pollution taxes paid and fines paid in violation of environmental regulations. Indirect costs are the active expenditures of enterprises, such as the cost of purchasing environmentally-friendly production equipment to reduce pollution, and the costs of transferring pollution-intensive industries to weakly regulated areas. The latter refers to the decline of corporate image and the generation of opportunity costs due to moral hazard due to pollution discharge and negative pollution control. It can be seen that with the strengthening of environmental pressures, these costs of companies responding in a negative way will increase. Higher environmental costs have squeezed the company's productive costs and technological innovation investment, which has a negative effect on the daily production activities and technological research and development behavior of the enterprise, thereby inhibiting the company's technological innovation and improvement in production efficiency[2].

\subsection{The impact of enhancement}

When the regulated enterprises recognize the importance of environmental protection and will be in a stronger regulatory environment for a longer period of time, they will seek ways to fundamentally reduce or solve pollution problems in the production process. To fundamentally reduce or solve the problem of pollution in the production process. On the one hand, we need to improve the production process, reduce the discharge of pollutants in the production process, and carry out clean production. On the other hand, we must carry out the pollution that is inevitable during the production process, discharge after cleaning treatment and improve cleaning 
efficiency. These two measures impose higher requirements on existing production technologies and pollution treatment technologies, thereby forcing regulated enterprises to actively increase investment in technology research and development and improve the above processes through technological innovation. Applying technological innovations driven by environmental regulations to the production process can not only reduce environmental pollution problems, reduce environmental costs, improve resource utilization efficiency and production efficiency, but also show the society and the public that they are actively taking environmental protection responsibilities. In addition, in order to promote the development of a green economy, the government will encourage enterprises to improve their production technologies while enforcing environmental regulations, and will provide certain policy support, including tax incentives, special funds, credit preferences, green procurement, etc., thereby promoting corporate innovation[11].

\subsection{Comprehensive impact of environmental regulation on innovation}

Whether environmental regulation can have a positive effect on industrial upgrading through technological innovation mainly depends on the magnitude of the two effects of environmental regulation and the net effect between the two effects, that is, whether technological innovation driven by environmental regulation can partially or completely offset the increased costs of environmental regulation. With the same investment, the increase in environmental costs will have a squeeze effect on the production costs and R\&D costs of regulated enterprises, and then have an inhibitory effect on the company's production efficiency and technological innovation. At this time, the inhibitory effect of environmental regulations is stronger to hinder corporate innovation. Even if regulated enterprises take the initiative to increase technology R\&D investment and strengthen technology R\&D efforts in order to meet environmental standards, it takes a certain amount of time for the results of technological innovation activities and the application of innovation results to production practices. The results have not appeared, and it is difficult to offset the increase in environmental costs. When the technological innovation activities of regulated enterprises produce results, and gradually apply the innovation results to the production process, thereby improving the production process, improving cleaner production capacity, reducing pollutant emissions, and increasing resource utilization and production efficiency, at this time technological innovation gradually offset the cost increase brought by environmental regulation, and the promotion effect of environmental regulation can be reflected. When the market behaviors adopted by enterprises make the promotion effect greater than the inhibition effect within a certain period of time, environmental regulations will eventually promote corporate innovation.

\subsection{Trend description}

Using the data of China's provinces from 2008 to 2017, a trend chart of technological innovation level and environmental regulation intensity is obtained as figure 1. The data source is China Statistical Yearbook. R\&D is used to measure the level of technological innovation, and industrial pollution control investment is used to measure the strength of environmental regulations. It can be found that except for the 2017 data, which have obvious abnormalities, the level of technological innovation and the intensity of environmental regulations in other years show a positive correlation.

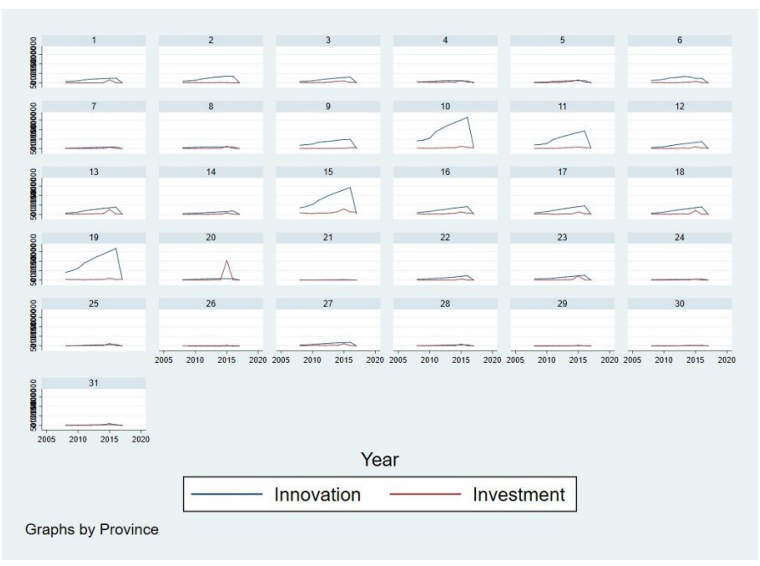

Figure 1. Annual trend chart of technological innovation level and environmental regulation intensity.

\section{Equations and Data Sources}

Using China's 2008-2017 data to examine the impact of environmental regulatory intensity on the level of technological innovation. The construction model is shown in equation (1):

$$
R \& D=\partial_{0}+\partial_{1} E R+\partial_{2} G D P+\partial_{3} F I X+\partial_{4} F D I+\varepsilon
$$

Among them, $R \& D$ represents technology investment, $E R$ represents the ability to detoxify domestic waste. $E R$ is measured by two indicators: the ability to harmlessly treat domestic waste and the amount of sulfur dioxide emissions. GDP represents gross national product per capita, FIX represents investment in fixed assets, FDI represents the proportion of foreign direct investment in GDP. The descriptive statistics of samples is as shown in table 1.

Table 1.Sample Descriptive Statistics

\begin{tabular}{|c|c|c|c|c|c|}
\hline Variable & Max & Min & Mean & Std.Dev. & Obs \\
\hline$R \& D$ & 17606.1 & 4616 & 10878.11 & 4337.314 & 10 \\
\hline$H P C$ & 680000 & 315000 & 482000 & 120000 & 10 \\
\hline$S O_{2}$ & 2321.229 & 875.4 & 1891.204 & 496.477 & 10 \\
\hline$G D P$ & 59660 & 24121 & 41257.5 & 11907.56 & 10 \\
\hline$F I X$ & 641000 & 173000 & 413000 & 165000 & 10 \\
\hline$F D I$ & 0.038 & 0.022 & 0.029 & 0.005 & 10 \\
\hline
\end{tabular}

This paper uses stata15.0 software to perform a regression analysis on the impact of environmental 
regulation intensity on the level of technological innovation. Test the impact according to model (1). The regression results are shown in Table 2 .

Table 2.Regression Results

\begin{tabular}{|c|c|c|}
\hline \multirow{2}{*}{$\begin{array}{c}\text { Explained } \\
\text { variable }\end{array}$} & $\mathbf{2}$ & $\mathbf{( 1 )}$ \\
\cline { 2 - 3 } & \multicolumn{2}{|c|}{$R \& D$} \\
\hline$H P C$ & $0.0111^{* * *}$ & \\
\hline & $(0.002)$ & $-0.5520^{* *}$ \\
\hline $\mathrm{SO}_{2}$ & & $(0.143)$ \\
\hline & & $0.2276^{* * *}$ \\
\hline$G D P$ & $0.2040^{* * *}$ & $(0.025)$ \\
\hline & $(0.023)$ & $0.0057^{* *}$ \\
\hline$F I X$ & 0.0005 & $(0.002)$ \\
\hline & $(0.002)$ & $-84,405.2867^{*}$ \\
\hline$F D I$ & $-94,541.9486^{* *}$ & $(34,134.683)$ \\
\hline & $(28,799.851)$ & $2,605.8832$ \\
\hline Constant & -363.6936 & $(1,834.676)$ \\
\hline & $(1,198.752)$ & 10 \\
\hline Observations & 10 & . \\
\hline
\end{tabular}

Note: $* * * * *$, and $*$ indicate that they are significant at the levels of $1 \%, 5 \%$, and $10 \%$, respectively.

The stronger the ability to harmlessly treat domestic waste, the stronger the intensity of environmental regulations and the greater the amount of sulfur dioxide emissions, the lower the intensity of environmental regulations. From the empirical results, HPC is significantly positively correlated with $\mathrm{RD}$, and $\mathrm{SO} 2$ is significantly negatively correlated with RD. This shows that as the intensity of environmental regulations increases, the level of technological innovation will increase.

\section{Summary}

According to the theoretical analysis, the intensity of environmental regulation has two effects on the level of technological innovation: suppression and promotion. This article uses 2008-2017 China's statistical data for empirical research, uses technology input to measure technological innovation level, and uses innocuous treatment of domestic waste and sulfur dioxide emissions as explanatory variables to perform regression. The empirical results all show the positive impact of the intensity of environmental regulations on the level of technological innovation.

The government should increase the incentives for technological innovation, especially green technological innovation, to stimulate the potential capabilities of technological innovation of various enterprises, and promote them to create new products more actively and efficiently. When formulating environmental protection policies and regulations, the government should not only consider controlling environmental pollution, but also consider whether the environmental policies introduced can encourage enterprises to carry out technological innovation and enhance competitive advantages. For example, the government should increase the penalties for environmental pollution, increase environmental protection subsidies, give full play to the positive role of environmental protection laws and systems in increasing environmental protection investment behavior of enterprises, establish appropriate reward and punishment measures, actively reward green output, and combine incentives and punishments to stimulate enterprises technological innovation and enhances competitiveness, thereby increasing economic performance, and promoting the comprehensive and coordinated development of enterprises.

Enterprises themselves should also actively cooperate with relevant environmental regulations issued by the government, make reasonable use of national incentive policies, increase investment in green technology innovation, improve environmental issues, reduce unnecessary waste of resources, achieve optimal allocation of resources, and increase labor production efficiency and improve innovation.

\section{References}

[1]PORTER M E.American's green strategy.Scientific American. J.4(1991): 168-189.

[2]Jaffe A B, Peterson S R, Portney P R, Stavins R N. Environmental - Regulation and the Competitiveness of United - States Manufacturing - What Does the Evidence Tell Us. Journal of Economic Literature. J.33(1995):132 163.

[3]Gray W B. The Cost of Regulation: OSHA, EPA and the Productiv-ity Slowdown. American Economic Review, J.77(1987): 998 - 1006.

[4]Jaffe A B, Peterson S R, Portney P R, Stavins R N. Environmental - Regulation and the Competitiveness of United - States Manufacturing - What Does the Evidence Tell Us. Journal of Economic Literature, J.33(1995):132 $-163$.

[5]Kneller R, Manderson E. Environmental Regulations and Innovation Activity in UK Manufacturing Industries. Resource and Energy Economics, J. 34(2012):211 - 235. [6]Miao Miao, Su Yuandong, Zhu Xi, Jiang Yushi, Zhang Hongyu. Impact of Environmental Regulations on Technological Innovation of Enterprises - - A Test of Intermediate Effects Based on Financing Constraints [J]. Soft Science, C.33 (2019): 100- 107.

[7]Zhao Hong. Impact of Environmental Regulation on China's Industrial Technology Innovation [J]. Economic Management, C.21 (2007): 57-61.

[8]Li Ping, Mu Xiuru. Analysis of the Differences in the Innovation Effect of Environmental Regulation Technology. Science \& Technology Progress and Policy, C.30 (2013): 97-102.

[9]Zhang Cheng, Lu Yan, Guo Lu, Yu Tongshen. Environmental regulation intensity and production technology progress. Economic Research, C.46 (2011): 113-124.

[10]Li Jing. Research on Environmental Regulation and Enterprise Technology Innovation Efficiency. China Economic Issues, C.4 (2013): 38-44.

[11]Ji Yujun, Song Jinze. Research on the Industrial Upgrade Effect of China's Environmental Regulations. Journal of Tianjin University of Commerce, C.1 (2020): 19-27. 